\title{
Efektivitas Busur Multiloop Edgewise Pada Kasus Crowding Berat Disertai Palatal Bite
}

\author{
Nolista Indah Rasyid, Prihandini Iman dan JCP Heryumani
}

*Program Studi Ortodonsia, PPDGS, Fakultas Kedokteran Gigi, Universitas Gadjah Mada

JI Denta No 1 Sekip Utara, Yogyakarta, Indonesia; e-mail: nolista@yahoo.co.id

\begin{abstract}
ABSTRAK
Mekanisme perawatan dengan Multiloop Edge Wise (MEAW) efisien dalam melakukan koreksi maloklusi berat dengan defleksi tekanan yang sangat rendah. Tujuan pemaparan kasus adalah evaluasi perawatan crowding berat disertai palatal bite menggunakan multiloop edgewise archwire. Seorang laki laki 15 tahun dengan maloklusi Angle kelas I tipe 1,4, skeletal kelas I dengan bimaksilari retrusif disertai bidental protrusif. Crowding berat pada regio anterior dan posterior serta palatal bite pada gigi 12, 11,21, 22 terhadap 42, 41, 31, 32, scissor bite pada gigi 15 terhadap 45, overjet $6,21 \mathrm{~mm}$ dan overbite $6,04 \mathrm{~mm}$. Bentuk lengkung gigi pada rahang atas parabola asimetri sedang pada rahang bawah omega asimetri. Lengkung gigi regio posterior mengalami kontraksi lateral dan lengkung gigi kearah anterior mengalami protraksi. Perawatan kasus dilakukan dengan menggunakan alat cekat teknik Edgewise dengan multiloop pada regio anterior dan posterior disertai pencabutan empat gigi premolar pertama. Hasil perawatan setelah 6 bulan menunjukkan crowding, palatal bite, dan scissor bite terkoreksi. Overjet menjadi 4,20 mm dan overbite $3,90 \mathrm{~mm}$. Bentuk lengkung pada rahang atas dan rahang bawah menjadi parabola simetris. Jarak intermolar rahang atas bertambah sebesar 2,11 mm dan rahang bawah bertambah sebesar $1,22 \mathrm{~mm}$.
\end{abstract}

Maj Ked Gi. Desember 2014; 21(2): 191 - 196

Kata kunci : Crowding, MEAW

\begin{abstract}
Effectiveness of multiloop edge wise arch in severe crowded case accompanied by palatal bite. MEAW appliance is a tehnique which is able to efficiently treat many cases including severe crowding with very low load deflection. The objectives of this study is to evaluate the treatment of severe crowding malocclusion with palatal bite using multiloop edgewise archwire. A 15 years old man with Angle class I type 1,4 malocclussion, class I sceletal with bimaxillary retrusion and bidental protusion. Severe crowding malocclusion in anterior and posterior region, palatal bite in 12, 11,21, 22 to 42, 41, 31, 32, scissor bite in 15 to 45, overjet $6,21 \mathrm{~mm}$ and overbite $6,04 \mathrm{~mm}$. asymmetry in both of dental arch, but the shape of the upper arch was parabola and lower arch was omega. Contraction of dental arch in posterior region and protraction in anterior region. This case was treated with extraction of four first premolar using multiloop edgewise arcwire tehnique, the loops were placed in anterior and posterior region. After six month of treatment the result showed that MEAW could correct severe crowding, palatal bite and scissor bite. Overjet became 4,20 mm and overbite became 3,90 $\mathrm{mm}$. Shape of upper and lower dental arch became symmetric parabola. Upper intermolar increased 2,11 $\mathrm{mm}$ and lower intermolar 1,22 $\mathrm{mm}$.
\end{abstract}

Maj Ked Gi. Desember 2014; 21(2): 191 - 196

Keywords: Crowding, MEAW

\section{PENDAHULUAN}

Crowding dapat terjadi karena ruang yang dibutuhkan untuk erupsi gigi pada posisi yang benar lebih besar dibandingkan dengan ruang yang tersedia pada lengkung gigi. Perbedaan antara ketersediaan lengkung rahang dengan lebar mesio distal gigi yang ada menimbulkan diskrepansi lengkung rahang dengan derajat keparahan mulai ringan sampai berat. ${ }^{1}$ Crowding sering disebabkan kurangnya pertumbuhan lengkung rahang untuk menampung gigi sehingga gigi tidak tumbuh pada posisi yang normal.
Kondisi crowding pada regio anterior dan posterior dapat menyebabkan retensi plak sehingga pasien kesulitan dalam menjaga kebersihan gigi dan mulut, hal ini dapat berakibat pada perubahan patologis jaringan periodontal serta memicu terjadinya karies gigi. Crowding memiliki pengaruh negatif pada sistem dentomaksilari yaitu permasalahan estetik yang merupakan faktor uama motivasi pasien untuk melakukan perawatan ortodontik. ${ }^{2}$ Perawatan crowding sangat diperlukan untuk mengatasi permasalahan estetika pasien serta membantu pasien dalam menjaga kebersihan 
gigi dan mulut yang optimal. ${ }^{3}$ Crowding juga dapat menyebabkan permasalahan pada fungsi oral yaitu kesulitan dalam pergerakan rahang (inkoordinasi otot atau nyeri), disfungsi sendi temporomandibular, permasalahan pengunyahan, penelanan dan bicara. ${ }^{4}$

Penilaian terhadap tingkat keparahan maloklusi dapat dilakukan dengan indeks Malalignment (Mal I), indeks ini diperkenalkan oleh Van Kirk dan Pennell untuk menilai letak gigi yang crowding. Kriteria penilaian dilakukan dengan memberi skor 0 sampai 2. Skor 0 untuk kondisi letak gigi yang teratur dalam deretan normal, skor 1 letak gigi crowding ringan dengan tipe 1 rotasi kurang dari $45^{\circ}$ dan tipe 2 penyimpangan kurang dari $1,5 \mathrm{~mm}$, skor 2 letak gigi crowding berat dengan tipe 1 rotasi lebih dari atau sama dengan $45^{\circ}$ dan tipe 2 penyimpangan lebih dari atau sama dengan $1,5 \mathrm{~mm} .{ }^{5}$

Palatal bite terjadi jika tepi mesial incisivus bawah mengenai palatum. Hal ini dapat disebabkan oleh supra-oklusi gigi Incisivus rahang atas atau rahang bawah, overjet yang berlebihan, infra-oklusi gigi molar, tinggi ramus mandibula, kebiasaan buruk (seperti bruxism, menghisap ibu jari), pertumbuhan rahang atas yang terlalu cepat, kelainan genetik. ${ }^{6}$ Perawatan deep overbite perlu dilakukan karena dapat menyebabkan kelainan pada sendi temporo mandibular, trauma pada gingival dibagian palatal dan terlihat gum smile pada pasien. ${ }^{7}$

Perawatan ortodontik bertujuan untuk memperoleh keharmonisan profil muka, relasi dan fungsi pengunyahan yang baik, serta stabilitas hasil akhir. Perawatan ortodontik dapat meningkatkan fungsi dan estetika. ${ }^{7}$ Perawatan ortodontik pada kasus crowding dapat dilakukan dengan alat ortodontik cekat dengan pemakaian multiloop arcwire. Pemakaian multiloop sangat efektif dalam koreksi crowding dengan memberikan defleksi tekanan yang ringan. ${ }^{8}$ Multiloop juga mampu melakukan koreksi pada maloklusi yang berat serta dapat memberikan pergerakan individual gigi dalam arah tiga dimensi. Tujuan pemaparan artikel ini untuk memperlihatkan efektivitas pemakaian multiloop pada kasus crowding berat disertai palatal bite dengan waktu perawatan yang cukup singkat. Pemakaian multiloop meliputi regio anterior dan posterior dengan variasi bentuk loop memberikan kombinasi arah gaya untuk koreksi malposisi gigi individual. ${ }^{9}$ Penulisan laporan kasus ini telah mendapat persetujuan dari pasien dan pasien tidak keberatan jika kasus tersebut dipublikasikan dalam majalah IImiah Kedokteran Gigi.

\section{METODE}

Pasien laki-laki, umur 15 tahun datang ke klinik Ortodonsia RSGM Prof. Soedomo dengan keluhan gigi depan atas tampak maju, gigi atas dan bawah tampak tidak beraturan sehingga terlihat tidak rapi, mengganggu penampilan, dan mengurangi rasa percaya diri. Riwayat kesehatan pasien baik, tidak menderita penyakit yang dapat menghambat perawatan ortodontik. (Gambar 1)

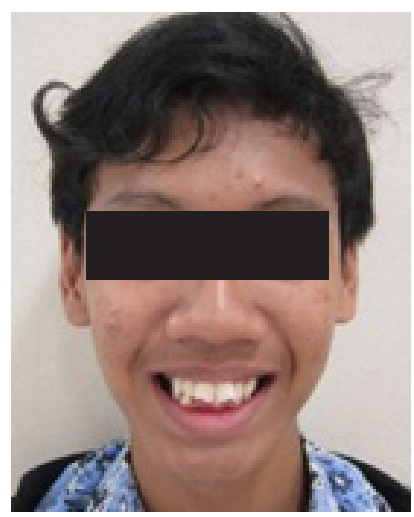

(A)

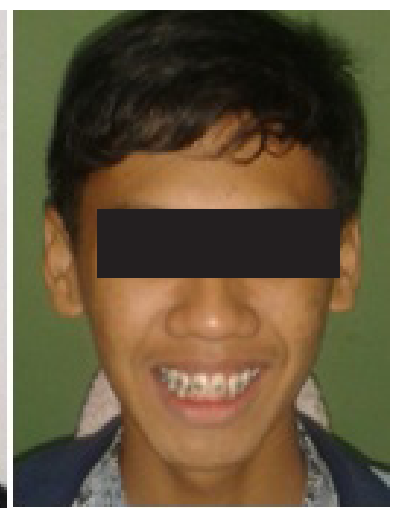

(B)
Gambar 1. Foto tampak depan sebelum (A) dan setelah 6 bulan perawatan $(B)$

Pemeriksaan intra oral memperlihatkan palatum arah vertikal dalam, bentuk lengkung gigi rahang atas parabola asimetri, bentuk lengkung gigi rahang bawah omega asimetri. Susunan gigi regio anterior rahang atas dan rahang bawah crowding berat dengan skor 2 berdasarkan indeks Malalignment (Mal I). Palatal bite pada gigi 22, 21, 11, 12 terhadap 42, 41, 31, 32 dan scissor bite pada gigi 15 dengan 45. Hubungan molar pertama kanan kelas I sedangkan hubungan molar pertama kiri kelas III. Berdasarkan perhitungan metode Pont lengkung gigi regio premolar mengalami kontraksi sebesar 10,31 mm dan regio molar sebesar 12,90 $\mathrm{mm}$ termasuk dalam kontraksi berat. Perhitungan Korkhaus menyatakan pertumbuhan lengkung gigi 


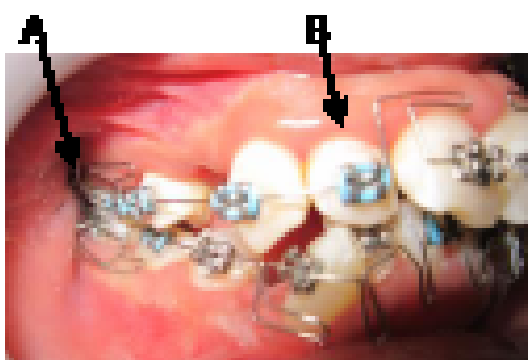

(A)

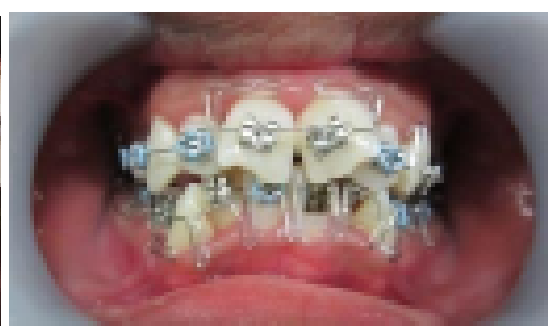

(B)

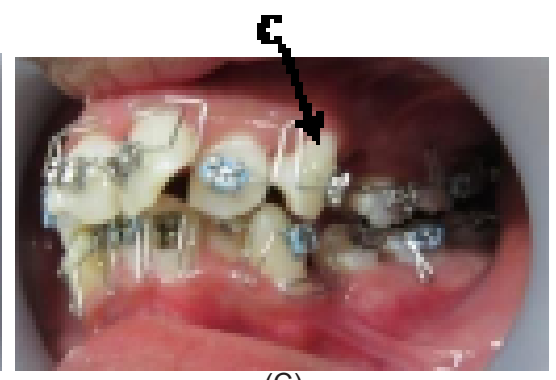

(C)

Gambar 2. Foto insersi alat dengan multiloop edgewise archwire, (A) T-Loop, (B) L-Loop, (C) vertikal loop

ke arah anterior mengalami protraksi sebesar 2,39 mm. (Gambar 3)

Hasil analisa sefalometri menggunakan metode Steiner menunjukkan hubungan skeletal kelas I dengan maksila dan mandibula retrusif disertai bidental protrusif. Analisa jaringan lunak menunjukkan bibir atas $3 \mathrm{~mm}$ didepan garis Steiner dan bibir bawah terletak $7 \mathrm{~mm}$ di depan garis Steiner. (Gambar 4; tabel 1)

Perawatan yang dilakukan bertujuan mengoreksi crowding pada regio anterior dan posterior pada rahang atas dan rahang bawah, mengoreksi palatal bite, mengoreksi scissor bite, pelebaran lengkung regio postrior dan retraksi gigi anterior menggunakan alat cekat teknik edgewise dengan multiloop. Berdasarkan perhitungan kebutuhan ruang dengan determinasi lengkung dan set up model kesling pada kasus ini, kekurangan ruang untuk rahang atas sebesar $9,90 \mathrm{~mm}$ dan rahang bawah sebesar $12,27 \mathrm{~mm}$. kekurangan ruangan diperoleh dengan pencabutan empat gigi premolar pertama.

Perawatan menggunakan alat cekat teknik edgewise dengan multiloop. Tahap pertama dilakukan levelling dan unravelling, koreksi crowding, palatal bite, scissor bite dan pelebaran lengkung regio posterior. Pada tahap levelling dan unraveling digunakan archwire ukuran 0,014 inchi disertai multiloop pada regio anterior dan posterior. Bentuk loop terdiri dari vertikal loop yang berada pada interdental gigi 22-23, 25-26, 36-35, 33-32, 3141, 41-42, 42-43, mesial 45, L loop pada interdental gigi 12-11, 21-22, distal gigi 33 dan 43, T loop pada interdental gigi 17-16, 16-15, 46-47. (Gambar 4) Setelah terjadi levelling dan unraveling, archwire diganti dengan plain archwire ukuran 0,016 inchi dilanjutkan tahap depression untuk koreksi palatal bite dengan e loop pada distal gigi 12, 22, 32, dan 42 dan gable bend. (Gambar 2)

Tahap kedua dilakukan retraksi gigi kaninus menggunakan rektanguler archwire ukuran 0,016 x 0,022 inchi dengan vertikal loop, chinched back archwire pada distal gigi molar yang diperpendek setiap kontrol dengan menarik wire pada distal bukal tube sampai retraksi selesai. Pada saat retraksi kaninus, jika gigi kaninus mengalami tipping ke distal dan gigi premolar kedua tipping ke mesial dapat dilakukan uprighting untuk menegakkan gigi tersebut dengan menggunakan uprighting loop dengan elastik.

Tahap ketiga dilakukan retraksi gigi anterior dengan vertikal loop pada distal gigi 12, 22, 32, dan 42 dalam keadaan aktif dengan menarik chinched back pada distal molar tube sampai retraksi selesai. Tahap keempat dilakukan penutupan ruang di bagian posterior dengan mesialisasi gigi posterior. Tahap akhir dilakukan perbaikan inklinasi gigi dengan melakukan first order bend, second order bend dan third order bend.

Tahap insersi archwire, beberapa braket dilakukan ligasi terlebih dahulu karena archwire tidak dapat masuk kedalam slot braket disebabkan kondisi yang sangat crowding. Setelah 6 bulan perawatan, crowding anterior dan posterior telah terkoreksi dengan gigi telah berada pada lengkung gigi, bentuk lengkung pada rahang atas dan rahang bawah menjadi parabola simetris (Gambar 3 dan 5). Palatal bite telah terkoreksi, overbite awal 6,04 $\mathrm{mm}$ menjadi $3,90 \mathrm{~mm}$. Inklinasi gigi depan atas labioversi dan rotasi telah terkoreksi, overjet awal 

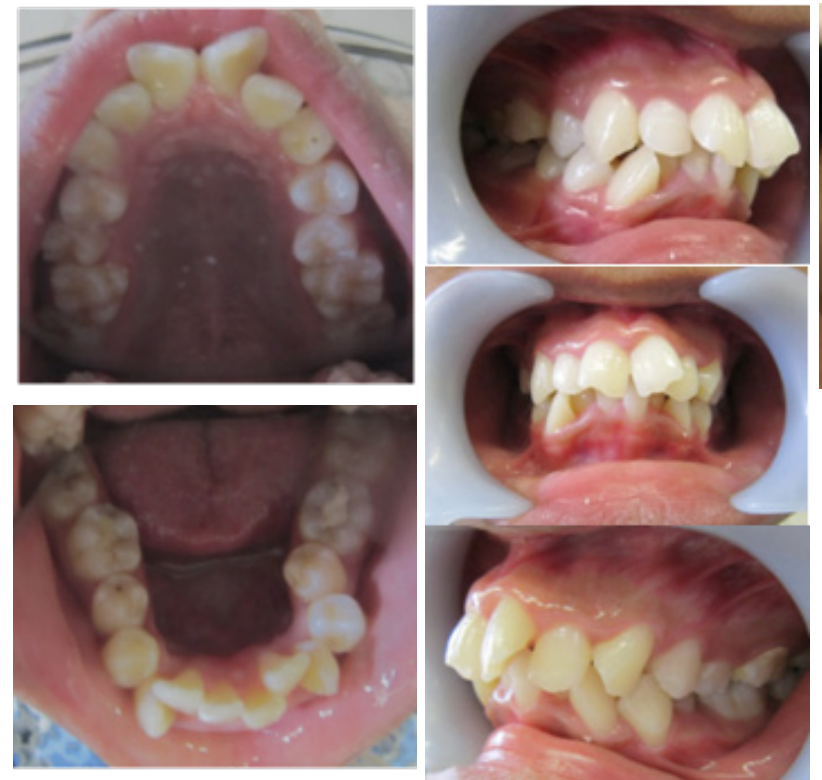

(A)
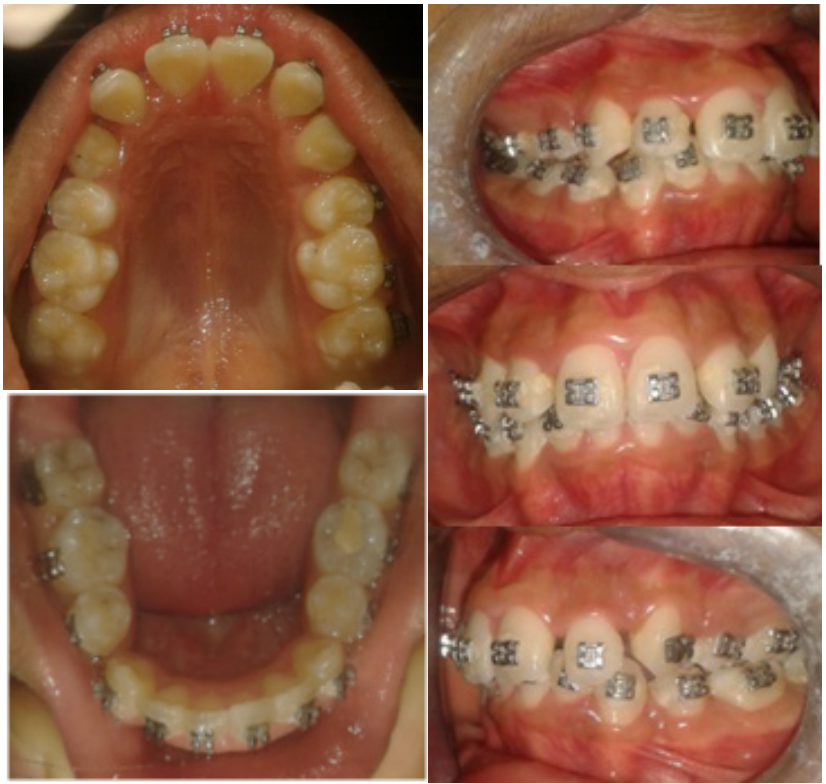

B

Gambar 3. Foto intra oral (A) sebelum dan (B) setelah 6 bulan perawatan

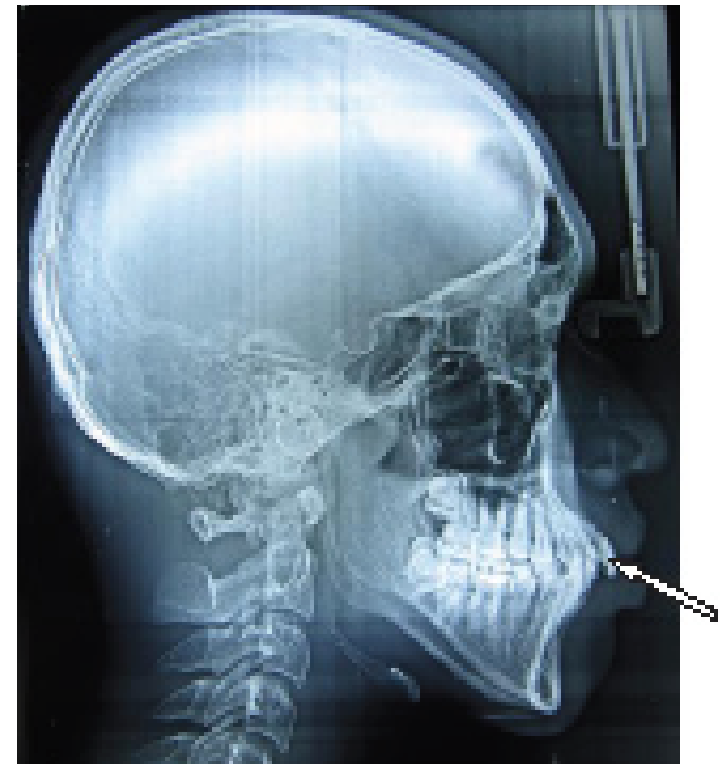

(A)

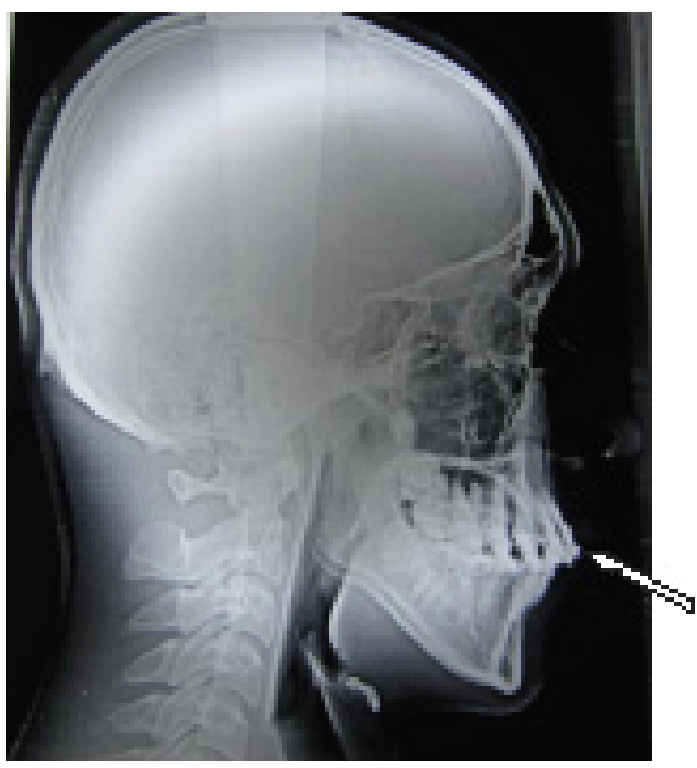

(B)

Gambar 4. (A) Tampak perubahan sudut I - NA pada foto sefalometri sebelum dan (B) setelah 6 bulan perawatan (tanda panah).

6,21 $\mathrm{mm}$ menjadi 4,20 $\mathrm{mm}$. Scissor bite pada gigi 15 dengan 45 telah terkoreksi dengan gigitan telah menjadi tonjol dan fossa. (Gambar 3) Berdasarkan hasil sefalometri terlihat perubahan pada inklinasi gigi insisif atas (I - NA) semula berjarak $15 \mathrm{~mm}$ dengan sudut $37^{\circ}$ menjadi $7 \mathrm{~mm}$ dengan sudut $22^{\circ}$. (Gambar 4 dan Tabel 1)
Saat ini pasien masih dalam tahap perawatan retraksi kaninus, setelah retraksi kaninus selesai akan dilanjutkan dengan retraksi anterior, perbaikan interdigitasi, dan oklusal adjustment. Setelah tahap perawatan aktif selesai akan dilanjutkan dengan pemakaian retainer untuk memperoleh kestabilan oklusi serta mencegah terjadinya relaps pasca perawatan ortodontik. 


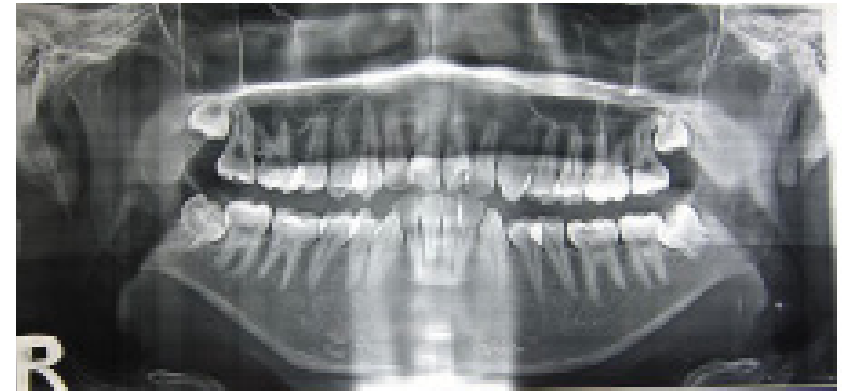

(A)

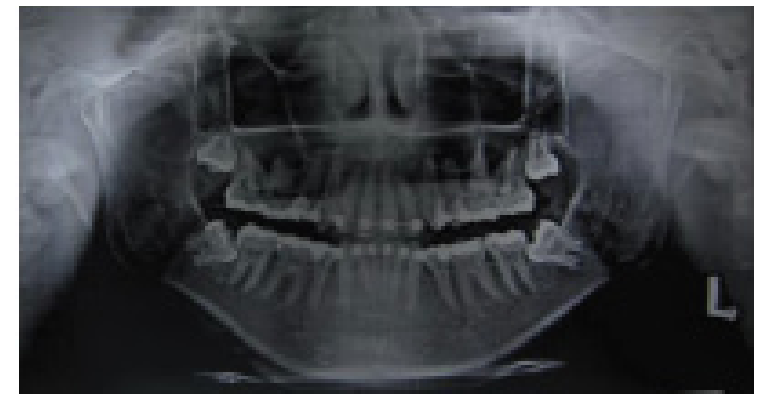

(B)

Gambar 5. (A) susunan gigi tampak tidak beraturan pada foto panoramik sebelum dan (B) setelah 6 bulan perawatan gigi geligi mencapai tahap levelling.

Tabel 1. Pemeriksaan sefalogram metode Steiner sebelum perawatan dan setelah 6 bulan perawatan.

\begin{tabular}{|c|c|c|c|c|}
\hline No & Pengukuran & Normal & $\begin{array}{c}\text { Pasien } \\
\text { Sebelum perawatan }\end{array}$ & $\begin{array}{c}\text { Pasien setelah } 6 \text { bulan } \\
\text { perawatan }\end{array}$ \\
\hline 1. & SNA & $82^{0}$ & $76^{\circ}$ & $74^{\circ}$ \\
\hline 2. & SNB & $80^{\circ}$ & $76^{0}$ & $72^{0}$ \\
\hline 3. & ANB & $2^{0}$ & $0^{0}$ & $2^{0}$ \\
\hline 4. & $1-\mathrm{NA}(\mathrm{mm})$ & $4 \mathrm{~mm}$ & $15 \mathrm{~mm}$ & $7 \mathrm{~mm}$ \\
\hline 5. & Sudut 1 - NA & $22^{0}$ & $37^{\circ}$ & $22^{0}$ \\
\hline 6. & $1-\mathrm{NB}(\mathrm{mm})$ & $4 \mathrm{~mm}$ & $9 \mathrm{~mm}$ & $8 \mathrm{~mm}$ \\
\hline 7. & Sudut $1-N B$ & $25^{0}$ & $28^{0}$ & $23^{0}$ \\
\hline 8. & Sudut $1-1$ & $130^{\circ}$ & $114^{0}$ & $129^{\circ}$ \\
\hline 9. & Bd oklusal - SN & $14^{0}$ & $15^{0}$ & $16^{0}$ \\
\hline 10. & Go $G n-S N$ & $32^{0}$ & $41^{0}$ & $44^{0}$ \\
\hline
\end{tabular}

\section{PEMBAHASAN}

Biomekanika perawatan dengan multiloop edgewise archwire menghasilkan pergerakan gigi yang sangat efektif, pada kasus ini crowding telah mulai terkoreksi pada tiga bulan perawatan. Setelah 6 bulan perawatan, crowding telah terkoreksi (Gambar 3). Pemakaian L-loop efektif dalam memberikan gaya uprighting pada gigi geligi yang mengalami tilting akan tetapi pemakaian loop pada tahap awal perawatan memberikan rasa tidak nyaman pada pasien, sehingga disarankan untuk memakai wax ortodontik untuk mengurangi iritasi mukosa. Hasil perawatan setelah 6 bulan menunjukkan palatal bite telah terkoreksi, akan tetapi secara klinis masih tampak deep bite meskipun overbite telah berada dalam rentang normal yaitu $3,90 \mathrm{~mm}$. Pada perawatan tahap rertaksi anterior perlu direncanakan pemakaian L-loop pada distal insisivus lateral dengan pemberian step kearah gingival pada kawat di regio anterior untuk memberikan efek intrusi sehingga deepbite dapat terkoreksi.

Multiloop archwire memberikan pergerakan dalam tiga arah yaitu vertikal, horizontal dan rotasi sehingga mampu melakukan koreksi terhadap malposisi gigi individual dengan menghasilkan pergerakan gigi individual, mengubah inklinasi dataran oklusal sehingga palatal bite dapat terkoreksi, menghasilkan kontak interkuspal, menegakkan inklinasi gigi pada rahang bawah, koordinasi dari lebar kedua lengkung dan torque gigi posterior. ${ }^{10}$ Pemakaian multiloop meliputi regio anterior dan posterior dengan variasi bentuk loop memberikan kombinasi arah gaya untuk koreksi malposisi gigi individual. ${ }^{9}$

Pergerakan gigi individual yang dihasilkan dari multiloop archwire lebih seragam dan seimbang serta memiliki kelebihan dalam pergerakan distal 
enmasse pada gigi mandibula. ${ }^{11,12}$ Multiloop archwire efektif dalam meneliminasi crowding akan tetapi dapat juga meningkatkan dimensi vertikal sehingga memberikan dukungan oklusi yang stabil. 9 Mekanisme multiloop archwire efektif dan serba guna dalam koreksi maloklusi seperti open bite, deep overbite, klas II, klas III dan maloklusi dengan deviasi midline akan tetapi tidak memberikan garansi keberhasilan perawatan sehingga perawatan dengan multiloop archwire membutuhkan diagnosis dan rencana perawatan yang tepat. Pemilihan bentuk dan penempatan loop perlu diperhatikan sesuai tujuan perawatan yang diinginkan serta detail saat melakukan bengkokan pada kawat harus tepat untuk mendapatkan hasil yang optimal. ${ }^{13}$

\section{KESIMPULAN}

Perawatan menggunakan MEAW dapat mengoreksi malposisi gigi dengan durasi perawatan yang singkat. Pembuatan bengkokan pada kawat harus dilakukan dengan tepat untuk menghasilkan pergerakan yang optimal, untuk itu perencanaan perawatan dengan menggunakan terapi MEAW membutuhkan penegakan diagnosa serta rencana perawatan yang tepat untuk mencapai hasil perawatan yang memuaskan.

\section{DAFTAR PUSTAKA}

1. Bernale E, Flores, C. Dental Morfhology and crowding. Angle Orthod. 2006 ; 76(1): 20-25

2. Bishara SE. Textbook of Orthodontics. W. B. Saunders Company. Philadelphia; 2001. p. $442-4$

3. Rizvi HM., Sikder MA., Hossain MZ. Orthodontic Treatment of Severe Crowding Malocclussion with Extraction of Premolars. BJO \& DFO. 2012; 2 (2): 30-33.

4. Profitt. WR. Contemporary Orthodontics, 4th ed., Philadelphia: Mosby Elsevier; 2007. p.233.
5. Dewanto H, Aspek-aspek Epidemiologi Maloklusi. Yogyakarta: Gajah Mada University Press; 1993; h.158-165.

6. Naeem, Saqib., Asad, Saad. Prevalence of Deep overbite In Orthodontic Patients, Pakistan Oral \& Dental Journal. 2008; 28 (2):189-192

7. Yang WS, Kim BH, Kim TH. A Study of regional Load Deflection rate of Multiloop Edgewise Archwire. Angle Orthod. 2001; 71 (2): 103-9.

8. Coro JC, and Coro IM. MEAW Therapy. Orthodontic Products. 2012; 19(9): 18

9. Kawagoe T, Akimoto S. Orthodontic treatment of severe crowding malocclusion with temporomandibular joint closed lock by means of multiloop edgewise archwire : A case report. J Stomat. Occ. Med. 2010; 3: 49-60.

10. He S, Gao J, Wamalwa P, Wang Y, Zou $S$, and Chen S. Camouflage Treatment of Skeletal Class III Malocclusion with Multiloop Edgewise Archwire and Modified Clas III Elastics by Maxillary Miniimplant Anchorage. Angle Orthod. 2013; 83(4): 630-640.

11. Young IC, Soo JS, and Seung HB. Three Dimensional Finite Element Analysis in Dental En Masse Movement of The Maxillary Dentition with The Multiloop Edgewise Archwire. Eur J of Orthod. 2004; 26(3): 339-345.

12. Seung HB, Soo JS, Sug JA, Young IC. Initial Effect of Multiloop Edgewise Archwire on the Mandibular Dentition in Class III Malocclusion Object. Three Dimensional Finite Element Study. Eur J of Orthod. 2008; 30(1): 10-15.

13. Kim YH, and Han UK. The Versatility and Effectiveness of the Multiloop Edgewise Archwire (MEAW) in Treatment of Various Malocclussions. World J Orthod. 2001; 2: 208218. 